\title{
The Spatial Value of Information
}

\author{
Agnese Galeffi \\ Vatican School of Library Science, Cortile del Belvedere, V-00120 Vatican City, \\ <agnese.galeffi@beic.it> or < galeffi@vatlib.it>
}

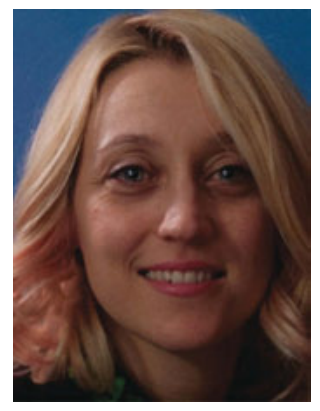

Agnese Galeffi (PhD in library science) teaches cataloguing and classification at the Vatican School of Library Science and works for the BEIC Digital Library as Cataloguing Coordinator. She is also a member of the IFLA Cataloguing Standing Committee and of the ISBD Review Group. She is also on the editorial board of Jlis, the Italian Journal of Library and Information science. Her interests include cataloguing theory and practice, conceptual models, data usability and their comprehension by users, and interface design.

Galeffi, Agnese. The Spatial Value of Information. Knowledge Organization. 40(3), 182-186. 11 references.

ABSTRACT: Conceptual models created by archival, library, and museum communities significantly influence the way in which data are displayed and aggregated. What's the reason behind this great attraction to conceptual models? Perhaps part of the explanation can be found in the growing importance of the visual representation of information. Concepts seem to be far more readily comprehended when represented in space in a visual way, a way that brings them closer to being images or maps. Like a geographical map, conceptual models disclose specific points, meaning entities, and identify relationships between these, thereby creating connections. If archives, libraries, and museums generate different "landscapes," how will the people who consult these at times discordant maps react? Which conceptual horizons should we offer our users? And will they be compatible with those they expect? Do we not perhaps risk increasing the chasm between information professionals and users?

Received 30 January 2013; Accepted 30 January 2013

Non si può comprendere tutto

per mezzo del cervello

senza far intervenire l'occhio o la mano.

The brain alone cannot fully

grasp all things without

the participation of one's hands and eye.

Benoit B. Mandelbrot, Conversazione con Giulio Giorello.

\section{Introduction}

The goal of this article is to pose some questions about the relationship between descriptive data and conceptual models, in particular entity/relationship models (e/r), and, above all, the best-known model employed in the field of librarianship, namely FRBR. In libraries, cataloguers select and organize data based on rules built into FRBR, which, quite often, significantly influences the way in which said data are displayed and aggregated. However, the presentation of data can also be shaped by different logic systems, systems that are less rigid in comparison with those prescribed by an e/r model, and which, one would like to think, are open to the possibility of merging data into a single information system where descriptions are created in different environments, not necessarily just libraries. When choosing ways of presenting data, a recognition of the spatial value of information can certainly be useful.

\section{Conceptual models in libraries, archives, and museums}

Museums, archives, and libraries share the vital task of preserving cultural heritage, in other words, works of art, documents, and literary or scientific works expressed in various forms on a wide range of physical media. Preservation is aimed at ensuring that such objects will remain intact and available for consultation and study not only today, but also far into the future. Over the course of time, various methods of description have been devised; these consist of the rules, norms and standards, etc., that 
allow library users to locate items within a system, whether it be an inventory, list, catalogue, or discovery tool. In recent times, the value of these prescriptive tools has been the subject of analysis and criticism following the emergence of conceptual models. Conceptual models represent a simplified vision of reality, irrespective of implementation details. Why, then, are conceptual models so popular at the moment?

In the library cataloguing world, this trend began about fifteen years ago (in 1998), with the publication of a text titled Functional Requirements for Bibliographic Records (FRBR). FRBR is a conceptual model designed for the bibliographic world; it was created by IFLA and presents entities, relationships, and attributes without specifying the way of pinpointing them and the protocols used to record them in catalogues.

In FRBR (IFLA 1998, 10), "The entity-relationship structure and the mapping of attributes and relationships to user tasks are used as the basis for the study group's recommendations on a basic level of functionality for records created by national bibliographic agencies." The analysis that resulted in the creation of FRBR took, as its starting point, the results obtained from the application of cataloguing rules. A conceptual model was arrived at by means of a process of abstraction of the products of the descriptive phase. Normally, however, the proper sequence to follow when constructing a conceptual model adopts, as its starting point, the real world or, more precisely in the case under discussion, the documentary/artistic/bibliographical/scientific world. Only an analysis of the fundamental characteristics identified in resources will allow one to arrive at an abstract conceptual model. This is the starting point for what's seen as the world of representation, meaning to say a combination of norms, standards, and applications (CNEDA 2012, 1). As Le Boeuf $(2005,8)$ said, "FRBR models what we do, not what we should do." How is it possible, then, that a model which came into being with the initial objective of arriving at a basic agreement for the handling of records produced by national bibliographies eventually became a conceptual model?

Setting aside a few criticisms (for example, the accusation of "oversimplification" put forward by Patrick Le Boeuf), FRBR has yielded numerous important studies of a theoretical nature as well as practical applications. FRBR has become a representation of knowledge, and its applications (norms, software, display methods, etc.) aim to supply users with a coherent and aggregate picture of the products of literary activity, but it is poorly adapted to materials of other kinds, such as archival documents, works of art, maps, etc. (Taylor 2007).

Almost contemporaneously with the emergence of FRBR, in 1996, the International Council for Museums started to develop the CIDOC conceptual reference model, an ontology aimed at the integration, mediation, and exchange of information generated by cultural heritage institutions. The archival community has never concealed its perplexity in regard to conceptual models of the FRBR type. "The key entity in the FRBR model (i.e., the work), cannot adequately represent the central unit of archival organization (i.e., the collection), FRBR has little impact on archival control" (Thurman 2007, 97). Collections and fonds, key components in archival organizations, are not represented in FRBR, and it becomes difficult to make them fit the definition of a work as "a distinct intellectual and artistic creation" as proposed by FRBR. Nevertheless, recently in Spain, the Comisión de Normas Españolas de Descripción Archivística published the Modelo Conceptual de Descripción Archivistica y Requisitos de Datos Básicos de las Descripciones de Documentos de Archivo, Agentes y Funciones (MCDA), which it openly declared to be directly inspired by IFLA's model.

$\mathrm{E} / \mathrm{r}$ conceptual models represent entities and the relationships between them (or between entities). However, from the moment these entities are defined based on the interests of the developers, the result will necessarily always represent the specific vision of a community, whether it be composed of librarians, archivists, or museum personnel. A conceptual model can be thought of as a vision, a particular way of looking at a sector or a phenomenon.

Each of these different spheres of cultural heritage has its own way of approaching resources (and therefore also of pinpointing and describing them). This is the reason why each specific conceptual model is adapted to a specific context and rather less so, or not at all, to others. The chief differences are not so much found in the pinpointed entities, but rather in the relationships between them.

\section{Why are conceptual models so attractive?}

So what's the reason behind this great attraction to conceptual models? Perhaps part of the explanation can be found in the growing importance of the visual representation of information.

Conceptual models are very useful within a specific domain for the purpose of evaluating the tools/instruments being used and critically rethinking the established descriptive tradition. But conceptual models also aspire to offer to those who carry out searches a picture of the resources, of the entities included in their creation, and the connections that exist between them.

Traditional cataloguing codes are composed of words, phrases, and paragraphs of text, and are distinctly twodimensional. The information is presented in a sequential 
way. The shift to conceptual models has brought with it a process of abstraction; at the same time, it has resulted in documents in which, in addition to the text, the meaning of information is explained through the use of drawings, lines, arrows, etc. Furthermore, the entity/relationship models (FRBR is one of these) make extensive use of graphic devices in a meaningful way. Concepts seem to be far more readily comprehended when represented in space in a visual way, a way that brings them closer to being "pictures" or images.

As Heidegger stated in Off the Beaten Track, "that the world becomes a picture at all is what distinguishes the essence of modernity" (2002, 68). One of the first advances made in the modern world was the reduction of the world itself into an image. And this reduction is an attempt to "paralyze" items of knowledge. Conceptual models are defined by means of a primary and decisive process for their development; this process is known as data modeling and is strongly characterized by design (Simsion et al. 2012). Data modeling is a form of reality mapping. This mapping activity does not, however, consist in a simple description of reality, but rather in a suggested "ideal" type. Most of the activities that one undertakes in this phase are, in fact, subjective (ideal), rather than objective (that is to say representative and real).

\section{Graphic representation in conceptual models}

Mapping consists in the determination of equivalences between two sets and in the assignment to each element of a set an equivalence in the other. Needless to say, when carrying out such work it is necessary to hold complete faith in the fact that, to each element, it is possible to assign a specific place, a sole and unique meaning. In a passage titled "The violence of mapping," Franco Farinelli $(2003,78)$ makes the following statement: "To make a map of something entails ... the preliminary reduction of a thing to a semblance of the thing it is, and therefore its transformation into an entity already possessing, by definition, each cartographic characteristic, already for the most part reduced to a diagram/figure." Like a geographical chart, conceptual models disclose specific points, meaning to say entities, and identify relationships between these, thereby creating connections. Limiting our discussion to the world of libraries, from the moment we use FRBR to define rules and develop software (an end not by any means considered in the original report), we are seeking to offer our users a sort of bibliographic geography, a map of recorded knowledge. And, within this map, we create travelable and navigable pathways: groupings of links, for example, composed of names, places and subjects. In this way, in addition to the data, we provide an interpretation. In order to build an effective information architecture, it is not enough to simply record data; the organization and representation of knowledge are two central concerns, and "the concept of an information architecture is a metaphor for the pattern of relationships that serves to provide structure for any collection of resources in whatever medium" (Jacob and Loehrlein 2009).

A decisive element in the perception of information depends on how said information is presented by the relative position it occupies in space (on the page or screen) and, therefore, how it is read or perceived. At heart, the same line of reasoning is also valid for cataloguing. Many cataloguing decisions are made based on the position occupied by a datum on resource, be it in absolute terms (on a cover, front page, etc.) or in relative terms (whether its positioned above or below in relation to another datum). A position represents a meaning, and the fact that a piece of information occupies a particular place frequently permits one to attribute a fixed meaning to it, and also to record it in a specific way. The value of access points is also fixed, within certain limits, by their position.

This is precisely what occurs in many languages. The position of a word in relation to others often provides the only indication of its value or meaning. In the phrase "the dog chases the cat," the syntax has immediately identified the position the subject occupies in the phrase, as well as the position of the direct object. In fact, if we invert the word order, the meaning of the phrase is turned upside down.

Returning to the realm of cataloguing, data are traditionally channelled into records (i.e., descriptions, access points, etc.) that formalize the contents into a sequence. The ISBD (International Standard Bibliographic Description) owed part of its success to the fact that the elements from which it is composed are interpretable thanks to their specific sequence and to the punctuation that distinguishes them, therefore, to repeat what has already been stated above, to the position that the elements occupy in respect to others. Not by chance, access points up until not very long ago were called "headings," a term that etymologically recalls the "at the head" position in relation to descriptive data.

To delve more deeply into a technical discussion, in the area of cataloguing, as well, there has been a shift from a mono-dimensional bibliographic vision, such as that typified by traditional index cards, to a two-dimensional one, such as that of bibliographic records/authority records, and then to a three-dimensional vision represented by the transposition to the semantic web of standard descriptions and models so as to render everything literally and semantically comprehensible to web users and data processing machines. 


\section{Different landscapes}

Relationships constitute the strong point in search systems set up in a digital environment. It is links that generate meaning. At the same time, however, relationships are ascribed, in the descriptive phase, on the basis of the meanings that one wants to attribute, which are strongly tied to the context in which they function. Is it possible to combine into a single information structure, a single "information architecture," the models created by cultural heritage institutions, archives, libraries, and museums? The risk one runs is of falling into the "préjugé «graphique»" that Lucien Febvre $(1949,69)$ speaks of, that is to say the comparison of things that have little or nothing in common, based on a merely superficial formal resemblance.

The creation of conceptual models certainly allows for greater reflection, but, perhaps at the same time, we are running the risk of causing a profound separation between the cultural heritage institutions, hence obstructing the possibility on the part of users to perform integrated searches within the different information systems. Returning once again to the analogy with geographical charts, if archives, libraries, and museums generate different "landscapes," how will the people who consult these at times discordant maps react? Which conceptual horizons should we offer our users? And will they be compatible with those they expect? Do we not perhaps risk increasing the chasm between information professionals and users?

Furthermore, in regard to the last ten years or so, it seems that we can confirm that conceptual models have become indispensable in the creation and development of information architecture systems. (This reflection might also lead us to ask ourselves how we coped in the past, how, that is, information was managed in the absence of conceptual models. Could it be that in traditional descriptive practice and the application of rules a sort of "philosophy" was implicit, a perception that has now been lost?) Should we perhaps ask why it is so difficult to represent items (resources) that we ourselves, meaning humanity as a whole, have created, modified, passed down through the ages, and managed? What is it that seems to evade us that we are trying to reconstruct using information architecture? A correct description no longer seems to be sufficient to the task. The description should also be functional. But the concept of "functionality" is always relative and, in order to be to fully expressed, must be contextualized.

To provide an example: a photograph of the Wrapped Reichstag by Christo might be held in 1) the Landesarchiv in Berlin, as testimony to a widely discussed collective artistic experience; 2) in a library collection, as a photograph, and 3) in a museum, as an image of an original work of art conceived by Christo and Jeanne-Claude. To simplify, in the archive, the photograph represents a document linked to evidence of the artistic activities promoted by the city; in the library, an image of specific dimensions represents the seat of government wrapped in fabric; and in a museum, it represents important evidence of a work of art that can no longer be viewed because of its ephemeral nature and rather short lifespan (it existed for just two weeks, in June 1995). The same item, then, will therefore be described functionally relative to these objectives. How, then, can we expect that a user will sometimes perceive this difference and adjust (almost instinctively) his/her conception of how knowledge is described, and therefore organized, in archives, libraries, and museums? Moreover, if it is impractical and inconsiderate to ask different cultural heritage sectors to utilize the same descriptive tools, is it not unrealistic to expect that they should adapt themselves to a universal conceptual model, to a unique vision, a sort of "one size fits all'?

Perhaps innovative solutions offered by cutting edge technology can come to our rescue. The possibility of having at our disposal ever more refined and sophisticated tools for the management and mining of information could, in fact, stimulate a more profound reflection on knowledge management issues. Pinpointing information resources in the digital context depends on something beyond the mere organization of data: it depends on the perception of said data, which, to return to our initial theme, is heavily conditioned by their spatial arrangement. It is not by mere chance that a number of prestigious institutions are currently examining the possibility of creating physical rooms that will represent a "fusion between built architecture and digital design sciences as a new Information Space" (Halatsch and Kunze 2007, 381). For example, the Swiss Federal Institute of Technology in Zürich (ETH) has created the Value Lab (http://www.valuelab.ethz.ch/), a place where the intensive application of technology and the possibility of utilizing multiple screens and projectors opens the way to conducting lessons and presentations in a more interactive way. At the same time, researchers are stimulated by the environment itself, an environment that helps them come up with new educational approaches and technological solutions.

\section{References}

CNEDA. 2012. Modelo conceptual de descripción archivística y requisitos de datos básicos de las descripciones de documentos de archivo, agentes y funciones parte 1: Tipos de entidad parte 2: Relaciones. Available http://www.mcu.es/archivos/docs/ NEDA_MCDA_P1_P2_20120618.pdf.

Farinelli, Franco. 2003. Geografia. Torino: Einaudi.

Febvre, Lucien. 1949. La terre et l'évolution humaine: Introduction géographique à l'bistoire. Paris: A. Michel. 
Halatsch, Jan and Kunze, Antje. 2007. Value lab: Collaboration in space. In Banissi, Ebad, Burkhard, Remo Aslak, Grinstein, Georges, Cvek, Urska, Trutschl, Marjan, Stuart, Liz, Wyeld, Theodor G, Andrienko, Gennady, Dykes, Jason, Jern, Mikael, Groth, Dennis and Ursyn, Anna eds. 11th International Conference Information Visualization. Los Alamitos, CA: IEEE, pp. 376-81.

Heidegger, Martin. 2002. Off the beaten track. Cambridge: Cambridge University Press.

IFLA Study Group on the Functional Requirements for Bibliographic Records. 1998. Functional Requirements for Bibliographic Records. Final report. München: K. G. Saur. Available http://www.ifla.org/files/assets/cataloguing/ frbr/frbr.pdf.

Jacob, Elin K. and Loehrlein, Aaron. 2009. Information architecture. In Cronin, Blaise, ed. Annual review of information science and technology. Silver Spring, MD: ASIS\&T, pp. 3,1-3,63.
Le Boeuf, Patrick. 2005. FRBR: Hype or cure-all? Introduction. In Le Boeuf, Patrick, ed. Functional Requirements for Bibliographic Records (FRBR): Hype or cure-all? Binghamton, NY: The Haworth Information Press, pp. 1-14.

Simsion, Graeme, Milton, Simon K., Shanks, Graeme G. 2012. Data modeling: Description or design? Information \& management 49: 151-63.

Taylor, Arlene G. 2007. Understanding FRBR. What it is and how it will affect our retrieval tools. Westport, Ct.: Libraries Unlimited.

Thurman, Alexander C. 2007. FRBR and archival materials: Collections and context, not works and content. In Taylor, Arlene G., ed. Understanding FRBR. What it is and how it will affect our retrieval tools. Westport, Ct.: Libraries Unlimited, pp. 97-102. 